\title{
Contemporary results of open aortic arch surgery
}

\author{
Mathew Thomas, MBBS, ${ }^{a}$ Zhuo Li, MS, ${ }^{a}$ David J. Cook, MD, ${ }^{b}$ Kevin L. Greason, MD, and \\ Thoralf M. Sundt, $\mathrm{MD}^{\mathrm{c}}$
} Objectives: The success of endovascular therapies for descending thoracic aortic disease has turned attention
toward stent graft options for repair of aortic arch aneurysms. Defining the role of such techniques demands un-
derstanding of contemporary results of open surgery.

\begin{abstract}
Methods: The outcomes of open arch procedures performed on a single surgical service from July 1, 2001 to August 30, 2010, were examined as defined per The Society of Thoracic Surgeons national database.

Results: During the study period, 209 patients (median age, 65 years; range, 26-88) underwent arch operations, of which 159 were elective procedures. In 65 the entire arch was replaced, 22 of whom had portions of the descending thoracic aorta simultaneously replaced via bilateral thoracosternotomy. Antegrade cerebral perfusion was used in 78 patients and retrograde cerebral perfusion in 1 . Operative mortality was $2.5 \%$ in elective circumstances and $10 \%$ in emergency cases $(P=.04)$. The stroke rate was $5.0 \%$ when procedures were performed electively and $11.8 \%$ when on an emergency basis $(P=.11)$. Procedure-specific mortality rates were $5.5 \%$ for elective and $10 \%$ for emergency procedures with total arch replacement, and $1.0 \%$ for elective and $10 \%$ for emergency procedures with hemiarch replacement. Stratified by extent, neurologic event rates were $5.5 \%$ for elective and $10 \%$ for emergency procedures with total arch and $4.8 \%$ for elective and $12.5 \%$ for emergency procedures with hemiarch replacement.
\end{abstract}

Conclusions: Open aortic arch replacement can be performed with low operative mortality and stroke rates, especially in elective circumstances, by a team with particular focus on the procedure. The results of novel endovascular therapies should be benchmarked against contemporary open series performed in such a setting. (J Thorac Cardiovasc Surg 2012;144:838-44)

Open surgical replacement of the aortic arch is an infrequently performed procedure in most practices. It is technically complex, particularly from a perfusion standpoint, demanding close cooperation and effective communication among all members of the surgical team. Additionally, the patient substrate requiring the procedure typically exhibits advanced cardiovascular disease, increasing the operative risk further. Because of these challenges and the success demonstrated with endovascular stent grafting of other aortic diseases in patients at high risk for open repair, endovascular approaches to the arch are being explored as an alternative to open repair. ${ }^{1-3}$ At the same time, the results of open surgical repair of arch disease have improved significantly with focused attention to the surgical, anesthetic, and perfusion-related challenges, as well as the introduction of selective antegrade cerebral perfusion (SACP), modern graft materials, and technical modifications such as use of branched grafts. ${ }^{4-6}$ Our own prior

From the Divisions of Cardiovascular Surgery ${ }^{\mathrm{a}}$ and Cardiovascular Anesthesia, ${ }^{\mathrm{b}}$ Mayo Clinic, Rochester, Minn; and Division of Cardiac Surgery, ${ }^{\mathrm{c}}$ Massachusetts General Hospital, Boston, Mass.

Disclosures: Authors have nothing to disclose with regard to commercial support.

Received for publication May 25, 2011; revisions received Aug 13, 2011; accepted for publication Sept 21, 2011; available ahead of print Dec 19, 2011.

Address for reprints: Thoralf M. Sundt, MD, Massachusetts General Hospital, 55

Fruit Street, Cox 652, Boston, MA 02114 (E-mail: tsundt@partners.org).

$0022-5223 / \$ 36.00$

Copyright (c) 2012 by The American Association for Thoracic Surgery

doi:10.1016/j.jtcvs.2011.09.069 examination of the subject documented an improvement in results over time, presumably as a result of the adoption of these techniques. ${ }^{4}$ Interpretation of this work, however, was complicated by the technical preferences of various individual surgeons performing the procedures. Therefore, to more precisely determine the risk of the procedure when approached by a team with particular focus on these procedures, we reviewed our results with open aortic arch replacement performed over the past decade on a single surgical service.

\section{PATIENTS AND METHODS}

Consecutive patients who underwent reconstruction of the aortic arch by 1 surgeon (T.M.S.) at the Mayo Clinic, Rochester, Minnesota, from July 1, 2001, to August 30, 2010, were included in the study. Preoperative variables and postoperative outcomes were recorded prospectively as per The Society for Thoracic Surgeons criteria. This computerized database was retrospectively reviewed with the approval of the Mayo Clinic Institutional Review Board with waiver of study-specific informed consent. We focused on perioperative mortality (defined as within 30 days of primary surgery or during the same hospital admission) and cerebrovascular events as primary outcomes. Secondary outcomes included other complications such as re-exploration for bleeding, renal failure, prolonged ventilation ( $>48$ hours), as well as surrogates for morbidity including length of hospital stay, 30-day readmission, and 5-year survivals.

\section{Surgical Technique}

Our technique for aortic arch surgery has evolved somewhat over time as detailed in a previous study, with increasing adoption of axillary artery cannulation in particular. ${ }^{4}$ Currently, patients with atherosclerotic disease, 


\section{Abbreviations and Acronyms}

DHCA $=$ deep hypothermic circulatory arrest

SACP $=$ selective antegrade cerebral perfusion

as opposed to that associated with connective tissue disease or bicuspid aortic valve, are most often cannulated for arterial inflow via the axillary artery using an 8-mm Dacron (DuPont, Wilmington, Del) graft regardless of the extent of planned repair (total or hemiarch replacement). Despite the trend toward lesser degrees of systemic cooling, we have persisted in cooling the patient for a minimum period of 30 minutes and toward a target nasopharyngeal temperature of $18^{\circ} \mathrm{C}$.

To ensure adequate neuroprotection, we initially used formal electroencephalography, although we now rely on the bihemispheral processed encephalogram. If an isoelectric state has not been achieved by 45 minutes of cooling, intravenous barbiturates are administered. Barbiturates are not otherwise routinely administered. Given a lack of convincing data that outcomes are actually improved with the use of near-infrared spectroscopy, we have not used this technology. To ensure adequate corporeal protection when total arch replacement in planned, we prefer to achieve a bladder temperature less than $23^{\circ} \mathrm{C}$. In the case of hemiarch replacement, a core temperature of $25^{\circ} \mathrm{C}$ and 30 minutes of cooling is considered acceptable given an expectation of a short arrest time. Acid-base management is performed with $\mathrm{pH}$-stat strategy during cooling and alpha-stat during rewarming.

Selective antegrade cerebral perfusion is routinely used as an adjunct to hypothermia for total arch replacement and in some instances of hemiarch replacement. This is typically instituted unilateral initially taking advantage of the right axillary artery inflow while branch graft reconstruction of the brachiocephalic vessels is completed adherent to the "arch first" concept advocated by Kouchoukos' group ${ }^{7}$ and others. ${ }^{8,9}$ Antegrade perfusion of all vessels can thereby be restored promptly and before construction of distal anastomoses. The initial flow is $10 \mathrm{~mL} \cdot \mathrm{kg}^{-1}$. $\min ^{-1}$ and is increased after restoration of antegrade flow in the left subclavian to achieve a left radial artery pressure of $50 \mathrm{~mm} \mathrm{Hg}$. Like others, ${ }^{10,11}$ we have not individually cannulated the brachiocephalic vessels for SACP in favor of keeping the operative field uncluttered. Stump pressures in the ipsilateral brachiocephalic and left carotid arteries are measured with balloon catheters if prolonged hypothermia is anticipated. We have largely abandoned retrograde cerebral perfusion and use it only for the purpose of flushing debris from the head. This technique was used in only 1 patient in this series.

\section{Patient Demographics}

As shown in Table 1, of 209 patients undergoing arch surgery during the study period, there were 131 men and 78 women with a median age of 64.5 years (range, 26-88 years). Three quarters of the procedures $(n=159)$ were elective. The most common diseases were degenerative aneurysms including bicuspid aortic valve disease $(124 ; 59 \%)$ followed by chronic $(36$; $17 \%)$ and acute $(28 ; 13 \%)$ dissections. About a third of the patients $(n=69)$ had previous cardiac surgery. Significant risk factors for postoperative morbidity included hypertension in $70 \%$; history of smoking in $62 \%$; congestive heart failure New York Heart Association class III or greater in $27 \%$; chronic lung disease in $16 \%$; previous history of stroke or transient ischemic attack in $10 \%$; peripheral vascular disease in $15 \%$; diabetes mellitus in $9 \%$; hypercholesterolemia in $32 \%$; and renal failure in $4 \%$. The mean body mass index was $27.9 \pm 5.8$.

\section{Operative Procedures}

In more than two thirds of cases $(n=104,72 \%)$, the replacement was hemiarch in extent (Table 2). In cases of hemiarch replacement, the underside of the aortic arch was resected in all instances well beyond the level of the takeoff of the innominate artery to a point opposite the takeoff of the subclavian artery. In 22 of the total arch cases, the descending thoracic aorta was concomitantly replaced via bilateral thoracosternotomy. An elephant trunk procedure was performed in $27(13 \%)$ patients. In $83 \%$ of the patients undergoing total arch repairs, the axillary artery was cannulated whereas the femoral artery $(8 \%)$ or central aorta $(9 \%)$ was equally cannulated in the rest. In half of the hemiarch patients, the central aorta was cannulated followed by the axillary artery in $39 \%$ and the femoral artery in $10 \%$. Selective antegrade cerebral perfusion was used in 78 $(37 \%)$ patients, including all of the total arch patients. Aortic root replacement was the most commonly performed concomitant procedure $(41 \%)$, whereas the aortic valve was replaced in $11 \%$ and coronary artery bypass grafting performed in $22 \%$.

The total bypass time (see Table 3 for operative times) for total arch replacement was longer than that for hemiarch replacement by approximately 1 hour ( 225 vs 165 minutes; $P<.001$ ), although this is affected by the number of patients undergoing concomitant replacement of the descending thoracic aorta. With the use of SACP, cerebral circulatory arrest times for total arch replacement were not dissimilar to those for hemiarch replacement (23 vs 20 minutes; $P=.79$ ), despite corporeal arrest times over an hour in the case of total arch surgery.

\section{Statistical Analysis Method}

Descriptive statistics for categorical variables are reported as frequency and percentage whereas continuous variables are reported as mean (standard deviation) or median (range) as appropriate. Categorical variables were compared between hemiarches and total arches using the $\chi^{2}$ test or Fisher exact test and continuous variables were compared using the 2-sample $t$ test or Wilcoxon rank sum test where appropriate. All statistical tests were 2-sided with the alpha level set at .05 for statistical significance.

\section{RESULTS}

Perioperative mortality occurred in $9(4.3 \%)$ patients. Patients undergoing emergency procedures had almost a 4-fold greater mortality rate $(10 \%)$ than those undergoing elective procedures $(2.5 \%)(P=.04)$. When stratified by the extent of repair and urgency, there were $3(5.5 \%)$ deaths among those undergoing elective total arch replacement and $1(1.0 \%)$ among those undergoing elective hemiarch replacement $(P=.12)$. Of the 5 deaths in the hemiarch replacement patients, 4 were in the setting of acute dissection. There were no deaths or neurologic complications in any of the hemiarch patients who had SACP. Of the total arch patients, all of whom had SACP, 4 (6.3\%) had a stroke, eventually resulting in their death. A significant burden of risk was among those undergoing replacement of the arch and descending thoracic aorta via thoracosternotomy, with 3 deaths and 3 strokes among these 22 patients $(13.6 \%$ each). Conversely, among the total arches excluding these very high-risk patients, the mortality rate and stroke rate were $2 \%$ each.

The most common cause of perioperative death was stroke, which occurred in 4 patients ( 3 ischemic and 1 hemorrhagic). Other causes included postoperative heart failure $(\mathrm{n}=1)$, rupture of the descending thoracic aorta after repair of an acute dissection related to severe labile hypertension $(\mathrm{n}=1)$, and renal failure $(\mathrm{n}=1)$. Two patients died at home after discharge from the hospital on postoperative 
TABLE 1. Patient demographics

\begin{tabular}{|c|c|c|c|c|}
\hline Variable & All $\operatorname{arch}(n=209)$ & Total $\operatorname{arch}(n=65)$ & Hemiarch $(n=144)$ & $P$ value \\
\hline Median age, y (range) & $65(26-88)$ & $63(27-88)$ & $63(27-88)$ & .362 \\
\hline Gender, male $(\%)$ & $131(63)$ & $36(55)$ & $95(66)$ & .143 \\
\hline Etiology (missing) & (5) & (2) & (3) & \\
\hline Degenerative (\%) & $124(59)$ & $35(54)$ & $89(62)$ & .278 \\
\hline Acute dissection $(\%)$ & $28(13)$ & $1(2)$ & $27(19)$ & $<.001$ \\
\hline Chronic dissection $(\%)$ & $36(17)$ & $17(26)$ & $19(13)$ & .022 \\
\hline Marfan syndrome $(\%)$ & $9(4)$ & $5(8)$ & $4(3)$ & .105 \\
\hline Mycotic pseudoaneurysm (\%) & $6(3)$ & $5(8)$ & $1(1)$ & .005 \\
\hline Other $(\%)$ & $1(0.5)$ & 0 & $1(1)$ & .036 \\
\hline \multicolumn{5}{|l|}{ Comorbidities } \\
\hline BMI & $27.1(17.3-63.9)$ & $26.4(19.1-43.0)$ & $27.7(17.3-63.9)$ & .077 \\
\hline Smoking ( $\%)$ & $129(62)$ & $42(65)$ & $87(60)$ & .563 \\
\hline Renal failure (\%) & 7 (3) & $2(3)$ & $5(3)$ & .760 \\
\hline Diabetes mellitus (\%) & $18(9)$ & $6(9)$ & $12(8)$ & .831 \\
\hline Hypertension (\%) & $149(71)$ & $47(72)$ & $102(71)$ & .827 \\
\hline Prior stroke $(\%)$ & $21(10)$ & $7(11)$ & $14(14)$ & .940 \\
\hline Prior MI $(\%)$ & $11(5)$ & $1(2)$ & $10(7)$ & .068 \\
\hline Prior cardiac surgery $(\%)$ & $69(33)$ & $27(42)$ & $42(29)$ & .078 \\
\hline Chronic lung disease (moderate to severe) $(\%)$ & $13(6)$ & $6(9)$ & $7(5)$ & .226 \\
\hline PVD $(\%)$ & $31(15)$ & $15(23)$ & $16(11)$ & .024 \\
\hline $\mathrm{EF}<40(\%)$ & $6(3)$ & $2(3)$ & $4(3)$ & .984 \\
\hline Hypercholesterolemia (\%) & $67(26)$ & $23(35)$ & $43(30)$ & .909 \\
\hline
\end{tabular}

$B M I$, Body mass index; $M I$, myocardial infarction; $P V D$, peripheral vascular disease; $E F$, ejection fraction.

days 15 and 26, respectively, and the causes of their death could not be determined. One of these patients had a perioperative stroke.

Neurologic complications occurred in 14 patients (overall, $6.7 \%$; elective procedures, $5.0 \%$ ). These included strokes in 13 patients and a transient ischemic attack in 1. All strokes were confirmed by computed tomography or

TABLE 2. Operative variables

\begin{tabular}{lcccr}
\hline \multicolumn{1}{c}{ Variable } & Total & Total arch & Hemiarch & $\begin{array}{c}\boldsymbol{P} \\
\text { value }\end{array}$ \\
\hline Elective $(\%)$ & $159(76.1)$ & $55(84.6)$ & $104(72.2)$ & .052 \\
Selective cerebral perfusion & & & & $<.001$ \\
None (\%) & $132(63.2)$ & $0(0)$ & $127(88.2)$ & $<.001$ \\
SACP (\%) & $78(37.3)$ & $65(100)$ & $13(9)$ & $<.001$ \\
RCP (\%) & $1(0.5)$ & $0(0)$ & $1(1)$ & .501 \\
Arterial cannulation & & & & \\
Central aorta (\%) & $80(38)$ & $6(9)$ & $74(51)$ & $<.001$ \\
Femoral artery (\%) & $19(9)$ & $5(8)$ & $14(10)$ & .637 \\
Axillary artery (\%) & $110(53)$ & $54(83)$ & $56(39)$ & $<.001$ \\
Other procedures & & & & \\
AVR (\%) & $23(11)$ & $8(12)$ & $15(10)$ & .686 \\
Aortic root (\%) & $86(41)$ & $18(28)$ & $68(47)$ & .008 \\
CABG (\%) & $46(22)$ & $18(28)$ & $28(19)$ & .183 \\
MVR/repair $(\%)$ & $5(2)$ & $1(1.5)$ & $3(2)$ & .790 \\
TV (\%) & $2(1)$ & $0(0)$ & $1(1)$ & .340 \\
ASD (\%) & $15(7)$ & $3(5)$ & $12(8.3)$ & .335 \\
\hline
\end{tabular}

$S A C P$, Selective antegrade cerebral perfusion; $R C P$, retrograde cerebral perfusion; $A V R$, aortic valve replacement; $C A B G$, coronary artery bypass grafting; $M V R$, mitral valve replacement; $T V$, tricuspid valve procedure; $A S D$, atrial septal defect repair. magnetic resonance imaging if the computed tomographic scan was indeterminate. On the basis of these studies, 12 appeared ischemic or embolic and 1 was hemorrhagic. The rate of stroke in patients undergoing emergency replacements $(11.8 \%)$ was over twice that of patients whose operations were performed on an elective basis $(5.0 \%)$ $(P=.11)$. Stroke rates were similar in the hemiarch $(6.9 \%)$ and total arch $(6.2 \%)$ cohorts $(P=.83)$. Of the 9 strokes in the hemiarch replacement patients, 3 were in the setting of acute dissection, 4 atherosclerotic aneurysm, and 1 each in the setting of endocardits and chronic dissection. The 1 patient who had a transient ischemic attack had undergone a hemiarch replacement for aneurysm.

Although the source of embolic material is a matter of conjecture, retrograde embolization from femoral artery cannulation was suspected in 3 of the 5 patients with stroke who had femoral cannulation for arterial inflow as imaging was highly suggestive of embolic etiology. In 1 patient the stroke appeared ischemic, and in 1 patient ischemic versus embolic etiology could not be adequately determined although carotid ultrasonography and magnetic resonance angiography were negative for any significant stenosis. The stroke rate associated with femoral cannulation, then, was 5 of 19 or $26 \%$. This also represents half of the hemiarch patients who had postoperative neurologic complications. These observations accounted in part for our shift over time to axillary cannulation as the preferred perfusion technique in the presence of atherosclerotic disease. With regard to the 7 patients who had a stroke despite axillary 
TABLE 3. Operative times

\begin{tabular}{lllcr}
\hline $\begin{array}{l}\text { Variable, min; } \\
\text { mean (range) }\end{array}$ & \multicolumn{1}{c}{ All arch } & \multicolumn{1}{c}{ Total arch } & Hemiarch & $\begin{array}{c}\boldsymbol{P} \\
\text { value }\end{array}$ \\
\hline Corporeal CA & $38.4(9-130)$ & $74.2(32-130)$ & $21.8(9-86)$ & $<.001$ \\
Cerebral CA & $21.1(3-72)$ & $23.2(3-72)$ & $19.7(3-56)$ & .793 \\
ACC & $110.3(7-236)$ & $126.4(7-236)$ & $102.9(24-221)$ & $<.001$ \\
CPB & $183.8(88-378)$ & $224.8(143-378)$ & $165.3(88-306)$ & $<.001$
\end{tabular}

$C A$, Circulatory arrest time; $A C C$, aortic crossclamp time; $C P B$, cardiopulmonary bypass.

cannulation, 1 had hemorrhagic stroke, 3 had embolic patterns, 2 ischemic patterns, and in 1 the radiologic appearance was nonspecific. The appearance of the magnetic resonance imaging scan was nonspecific between ischemia versus embolism for the 1 patient who had central cannulation and stroke.

Postoperative bleeding requiring reoperation occurred in $16(7.6 \%)$ patients as shown in Table 4 . The mean postoperative ventilator time was 36 hours. Mechanical ventilation was required for more than 48 hours in 24 (11.5\%) patients, of whom $11(46 \%)$ had undergone a "clamshell" incision. Renal failure requiring dialysis occurred in $6(3 \%)$ patients. Among patients surviving to discharge, the mean length of hospital stay was $8.6 \pm 5.2$ days (range, 3-34 days). Readmission within 30 days of primary operation occurred in 28 $(13 \%)$ patients for various reasons.

\section{DISCUSSION}

Historically, open surgical replacement of the aortic arch has carried a significant risk, with perioperative mortality rates from $7 \%$ to $12 \%$ reported for elective cases ${ }^{11,12}$ and even higher under emergency circumstances. ${ }^{13}$ There has been, however, a significant improvement in results over time ${ }^{4,14}$; despite this, there remains significant apprehension over subjecting a patient to these procedures. Although the volume of cases reported here is quite modest compared with those reported from many Asian and European centers of excellence, our study does show that with a focus on aortic disease using contemporary techniques, one can perform open aortic arch surgery with considerably lower perioperative mortality and morbidity than was historically the case, particularly under elective circumstances. Such contemporary results should be used as a comparator to hybrid repairs when trying to determine the place of each of these complementary therapies in current practice. Accordingly, although advances in endovascular techniques offer great promise for reducing further the morbidity associated with open surgery, open repair should remain a part of our armamentarium, particularly for younger, lower-risk patients and those with complex anatomy or connective tissue disorders.

Although overall the results are encouraging, the outcomes observed with bilateral thoracosternotomy were
TABLE 4. Postoperative complications and length of stay

\begin{tabular}{lcccr}
\hline \multicolumn{1}{c}{ Complication } & $\begin{array}{c}\text { All } \\
\text { arch }\end{array}$ & $\begin{array}{c}\text { Total } \\
\text { arch }\end{array}$ & Hemiarch & $\begin{array}{c}\boldsymbol{P} \\
\text { value }\end{array}$ \\
\hline Reoperation for bleeding (\%) & $16(8)$ & $11(17)$ & $5(4)$ & .001 \\
Neurologic deficit (\%) & $14(6)$ & $4(6)$ & $10(7)$ & .832 \\
Prolonged ventilation & $24(12)$ & $14(22)$ & $10(7)$ & .002 \\
$\quad>48$ h (\%) & & & & \\
Renal failure (\%) & $6(3)$ & $3(5)$ & $3(2)$ & .310 \\
Death $(\%)$ & $9(4)$ & $4(6)$ & $5(3)$ & .377 \\
Readmit $<30$ d (\%) & $28(1)$ & $6(9)$ & $22(15)$ & .260 \\
LOS, d; mean (range) & $8.9(3-34)$ & $10.9(5-31)$ & $7.6(3-34)$ & $<.001$ \\
\hline
\end{tabular}

LOS, Length of stay.

less gratifying than other total arch patients and raise questions about the place of this approach vis-à-vis elephant trunk type procedures, be they open or "frozen." The number of patients in this subgroup is too small to allow definitive conclusions and the spectrum of disease is broad, from congenital anomalies to extensive atherosclerotic disease. It is our impression that the operation is well tolerated and is, in fact, preferable in younger patients and those with complex anatomy such as cervical arch with coarctation or complex dissection. The results are less appealing, but options are also less, in those with mega-aorta owing to atherosclerotic disease. These individuals often have no distal landing zone, although current progress with fenestrated endograft technology is certainly advancing capabilities in this area. We, too, would agree that serious consideration should be given to treating such patients endovascularly if possible.

Our results are consistent with those reported by others with particular focus on aortic disease. The Mount Sinai group, also relying on a combination of deep hypothermia and SACP via the axillary artery, has observed improved results after open arch surgery over time. ${ }^{14}$ Their recently reported mortality rate for total arch replacement was $6.8 \%$, very similar to our results with total arch replacement $(6.3 \%) .^{5}$ This improvement in outcome over time with the adoption of cerebral protective strategies is not limited to the low-risk population as demonstrated by Minatoya and associates ${ }^{15}$ who reported results of arch surgery in octogenarians from 1995 to 2007. In this series, among elective cases, the overall mortality rate was $7.9 \%$ with a significant decrease in mortality $(4.5 \%)$ toward the later half of their study period subsequent to the adoption of similar brain protection strategy to ours. It must be noted, however, that in expert hands and a focus on aortic disease, Gega and colleagues ${ }^{16}$ achieved commendable results with deep hypothermia and circulatory arrest (DHCA) alone, reporting a mortality rate of only $3.6 \%$ for elective cases.

The basis for this improvement over time is likely multifactorial. In addition to specific technical modifications, there are likely other aspects of the "learning curve," the results of which are observed with many surgical procedures and likely include focused attention to various aspect of 
care, by all members of the team including, importantly, perfusion and anesthesia practices. We acknowledge some changes in our own practice over time, including an increasing aversion to femoral cannulation for arterial inflow because of concern about neurologic complications, as noted. In addition, conduct of hypothermic circulatory arrest is nontrivial from an anesthetic and perfusion standpoint. During the study interval, the use of DHCA in our institution increased significantly, leading to the formal adoption of perfusion protocols that had not been previously codified. Our belief is that improved cerebral protection has reduced postoperative neurologic injury, ${ }^{4}$ which in turn has been shown to reduce mortality. ${ }^{17}$ Indeed, most common single cause for mortality in our series was severe stroke, and we have increasingly come to recognize preventing neurologic injury as a critical objective in aortic arch surgery. We openly acknowledge tardiness in adopting some adjuncts such as SACP and axillary cannulation as compared with our European and Asian colleagues. Had we been more open, we might have improved our results early in the series.

We continue to rely on hypothermia as our primary neuroprotective strategy and to regard SACP as an adjunct, not a substitute. This is particularly the case for those patients in whom only a brief episode of circulatory arrest is anticipated, as argued by others. ${ }^{16}$ The virtues of SACP during periods of circulatory arrest lasting more than 30 minutes are well demonstrated in maintaining cerebral oxygenation and reducing derangements in cerebral metabolism. ${ }^{18-20}$ $\mathrm{We}^{4}$ have also previously demonstrated that, in cases with corporeal arrest times over 30 minutes, SACP "neutralizes" the impact of arrest time on stroke and mortality. The addition of axillary cannulation, which not only simplifies the surgical field but also directs flow (and embolic debris) retrogradely out of the innominate artery, has been shown by others to significantly reduce the mortality and morbidity after aortic arch repairs, especially in elective circumstances. ${ }^{11}$ As we have embraced Kouchoukos's "arch first" philosophy, the use of the axillary artery for antegrade perfusion also allows us to resume cerebral perfusion via all vessels as soon as the arch vessels are reconstructed, permitting time for unhurried distal reconstructions without fear of cerebral ischemia.

Despite the current trend toward combining SACP with only moderate hypothermia, we have been quite satisfied with our results using profound cooling and circulatory arrest. We cool for a minimum of 30 minutes to ensure even cooling. Estimation of brain temperature at surrogate sites may not be accurate ${ }^{21,22}$; thus, even if the target core temperature is reached early, the extra cooling time helps ensure adequate hypothermia at cellular levels. ${ }^{22,23}$ This may be responsible in part for our very infrequent observation of "transient neurologic dysfunction."

We have been reluctant to surrender the protective effects of hypothermia to the viscera as well. Renal-mesenteric ischemia has been shown to be a determinant of early death after DHCA. ${ }^{12,17}$ None of our patients had mesenteric ischemia and only $6(3 \%)$ of our patients had renal failure requiring dialysis. At an institutional level, we have not found DHCA to increase the risk of acute renal injury in thoracic aortic surgery. ${ }^{24}$ We acknowledge that other authors $^{25-28}$ have suggested that rates of other complications are higher with DHCA, but we have not found this to be the case. The group at Emory University advocates moderate hypothermic circulatory arrest with unilateral SACP as conferring adequate cerebral protection during arch repairs while avoiding the disadvantages of DHCA. In their series of 412 patients, the mortality rate was $7 \%$, overall neurologic events occurred in $8.7 \%$, and renal dysfunction was $4.6 \%$ with no apparent relationship to arrest temperature. ${ }^{29}$ Although a direct comparison with the Emory patient population has limitations for many reasons, the advantages of only moderate hypothermia are unconvincing to us inasmuch as there do not appear to be significant reductions in mean cardiopulmonary bypass time or reoperation for bleeding with their approach as compared with our study, and the time to discharge was actually somewhat shorter in our study ( $8.6 \pm 5.6$ days compared with the Emory group $10.3 \pm 7.5$ days). Further, the Emory group's excellent results with moderate hypothermia are not universally observed. Khaladj and associates ${ }^{30}$ reported a concerning mortality rate of $11.6 \%$ and total (permanent and temporary) neurologic event rate of $22 \%$, even with the use of SACP, in a series of 501 patients undergoing arch repairs with moderate hypothermic arrest. We have been particularly concerned about the adequacy of contralateral cerebral perfusion on the basis of our previously reported observations of stump pressures when inflow is via the right axillary artery, a concern that is only heightened at moderate perfusion temperatures. ${ }^{4}$

The principal utility of a study such as this hinges on its implications for selecting, for a specific patient, among the ever-expanding range of options for the treatment of aortic disease. The overall mortality rates recently reported for hybrid aortic arch surgery have ranged from $3.2 \%$ to $19 \%$ and stroke rates from $0 \%$ to $6.3 \%{ }^{1,2,31-33}$ In a recent metaanalysis of hybrid aortic arch surgery in 463 patients, the 30-day mortality rate was reported to be $8.3 \%$ and stroke rate, $4.4 \% .{ }^{31}$ Of course, as is the case for open repair, the results obtained will be critically dependent not only on the technique, but also on the patient substrate. Although they found no significant differences in overall mortality, stroke rates, or long-term survival between the hybrid and open groups, Milewski and colleagues ${ }^{2}$ from the Hospital of the University of Pennsylvania have advocated a hybrid approach for patients greater than 75 years inasmuch as the mortality rate in their experience for open surgery in this age group was $36 \%$. This is, however, significantly higher than the mortality rate we observed in our series 
( 2 of 37 aged greater than 75 years or $5.4 \%$ ). In addition, the hybrid stent-graft group had a rate of temporary spinal cord ischemia of $11 \%$, a complication we have not observed in any of our cases including the thoracosternotomy patients, and far higher than has been reported for staged repair of thoracic aortic aneurysms using the classic elephant trunk technique. ${ }^{34}$ In a separate report, the same group reported mortality and stroke rates for stented aortic arch grafts as high as $11 \%$ each. ${ }^{3}$ Although such outcomes may be appealing in some patients, such as those with extensive arch and descending thoracic disease, as was the case for many of the patients who underwent operation in our series via bilateral thoracosternotomy, for others it would likely be unacceptable.

Additional concerns about the endovascular approach include the lack of long-term results including reintervention and other complications, particularly for younger patients and those with connective tissue disease. The need for long-term surveillance after hybrid repairs is also a disadvantage.

\section{Study Limitations}

The current study has limitations inherent to retrospective studies. Selection bias and referral bias are significant ever present in surgical series, particularly in light of our study design, which reflects the practice of only 1 surgeon. The comparison with hybrid repairs is flawed as well, inasmuch as the extent of repair differs. A comparison with elephant trunk patients who underwent second stage repair might be more equitable, but the numbers in this instance would be too small to be meaningful. The ideal would be to conduct a prospective randomized study to compare hybrid with open procedures, but this does not seem imminent inasmuch there are significant limitations to the application of hybrid surgery and selection bias here too is unavoidable. Underreporting of late complications may result in ascertainment bias because a number of our patients are referred from distant centers and may have returned to their local hospital for postoperative issues after discharge. However, we make an effort to maintain communication and our providers are typically informed regarding such problems and document telephone calls. The more important question is whether our results can be generalized to all practice settings.

\section{CONCLUSIONS}

In summary, recent results of open aortic arch surgery, particularly under elective circumstances, are excellent when appropriate principles of neurologic and corporeal protection are followed. Accordingly, for the foreseeable future, there should continue to be a place for open surgical repair in appropriately selected patients. Although new technologies are welcomed, they should be considered complementary to open repair, and their place should be determined by comparison with current results and contemporary open techniques. Inasmuch as aortic arch disease is relatively uncommon, consideration of referral to high-volume centers in which all options are available should be considered.

\section{References}

1. Zhou W, Reardon M, Peden EK, Lin PH, Lumsden AB. Hybrid approach to complex thoracic aortic aneurysms in high-risk patients: surgical challenges and clinical outcomes. J Vasc Surg. 2006;44:688-93.

2. Milewski RK, Szeto WY, Pochettino A, Moser GW, Moeller P, Bavaria JE. Have hybrid procedures replaced open aortic arch reconstruction in high-risk patients? A comparative study of elective open arch debranching with endovascular stent graft placement and conventional elective open total and distal aortic arch reconstruction. J Thorac Cardiovasc Surg. 2010;140:590-7.

3. Bavaria J, Milewski RK, Baker J, Moeller P, Szeto W, Pochettino A. Classic hybrid evolving approach to distal arch aneurysms: toward the zone zero solution. J Thorac Cardiovasc Surg. 2010;140:S77-80; discussion, S86-91.

4. Sundt TM 3rd, Orszulak TA, Cook DJ, Schaff HV. Improving results of open arch replacement. Ann Thorac Surg. 2008;86:787-96.

5. Bischoff MS, Brenner RM, Scheumann J, Bodian CA, Griepp RB, Lansman SL, et al. Long-term outcome after aortic arch replacement with a trifurcated graft J Thorac Cardiovasc Surg. 2010;140:S71-6; discussion, S86-91.

6. Kouchoukos NT. One-stage repair of extensive thoracic aortic disease. J Thorac Cardiovasc Surg. 2010;140:S150-3; discussion, S185-90.

7. Kouchoukos NT, Masetti P, Mauney MC, Murphy MC, Castner CF. One-stage repair of extensive chronic aortic dissection using the arch-first technique and bilateral anterior thoracotomy. Ann Thorac Surg. 2008;86:1502-9.

8. Morishige N, Hayashida Y, Ito N, Takeuchi K, Akasu K, Iwahashi H, et al. Central arterial cannulation and the arch first method for aortic arch aneurysm repair. Ann Thorac Cardiovasc Surg. 2006;12:404-11.

9. Nishimura M, Ohtake S, Sawa Y, Takahashi T, Matsumiya G, Kagisaki K, et al. Arch-first technique for aortic arch aneurysm repair through median sternotomy Ann Thorac Surg. 2002;74:1264-6.

10. Svensson LG, Blackstone EH, Rajeswaran J, Sabik JF 3rd, Lytle BW, GonzalezStawinski G, et al. Does the arterial cannulation site for circulatory arrest influence stroke risk? Ann Thorac Surg. 2004;78:1274-84

11. Halkos ME, Kerendi F, Myung R, Kilgo P, Puskas JD, Chen EP. Selective antegrade cerebral perfusion via right axillary artery cannulation reduces morbidity and mortality after proximal aortic surgery. J Thorac Cardiovasc Surg. 2009; 138:1081-9

12. Kazui T, Washiyama N, Muhammad BA, Terada H, Yamashita K, Takinami M, et al. Total arch replacement using aortic arch branched grafts with the aid of antegrade selective cerebral perfusion. Ann Thorac Surg. 2000;70:3-8; discussion, 8-9.

13. Kazui T, Washiyama N, Muhammad BA, Terada H, Yamashita K, Takinami M, et al. Extended total arch replacement for acute type a aortic dissection: experience with seventy patients. J Thorac Cardiovasc Surg. 2000;119:558-65.

14. Strauch JT, Spielvogel D, Lauten A, Galla JD, Lansman SL, McMurtry K, et al. Technical advances in total aortic arch replacement. Ann Thorac Surg. 2004;77: 581-9; discussion, 589-90.

15. Minatoya K, Ogino H, Matsuda H, Sasaki H, Tanaka H, Kobayashi J, et al. Is conventional aortic arch surgery justifiable in octogenarians? J Thorac Cardiovasc Surg. 2010;139:641-5.

16. Gega A, Rizzo JA, Johnson MH, Tranquilli M, Farkas EA, Elefteriades JA. Straight deep hypothermic arrest: experience in 394 patients supports its effectiveness as a sole means of brain preservation. Ann Thorac Surg. 2007;84: 759-66; discussion, 766-7.

17. Okita Y, Takamoto S, Ando M, Morota T, Matsukawa R, Kawashima Y. Mortality and cerebral outcome in patients who underwent aortic arch operations using deep hypothermic circulatory arrest with retrograde cerebral perfusion: no relation of early death, stroke, and delirium to the duration of circulatory arrest. J Thorac Cardiovasc Surg. 1998;115:129-38.

18. Salazar JD, Coleman RD, Griffith S, McNeil JD, Steigelman M, Young H, et al. Selective cerebral perfusion: real-time evidence of brain oxygen and energy metabolism preservation. Ann Thorac Surg. 2009;88:162-9.

19. Di Eusanio M, Wesselink RM, Morshuis WJ, Dossche KM, Schepens MA. Deep hypothermic circulatory arrest and antegrade selective cerebral perfusion during ascending aorta-hemiarch replacement: a retrospective comparative study. J Thorac Cardiovasc Surg. 2003;125:849-54. 
20. Yamashita K, Kazui T, Terada H, Washiyama N, Suzuki K, Bashar AH. Cerebral oxygenation monitoring for total arch replacement using selective cerebral perfusion. Ann Thorac Surg. 2001;72:503-8.

21. Stone JG, Young WL, Smith CR, Solomon RA, Wald A, Ostapkovich N, et al. Do standard monitoring sites reflect true brain temperature when profound hypothermia is rapidly induced and reversed? Anesthesiology. 1995;82:344-51.

22. Hindman BJ, Dexter F. Estimating brain temperature during hypothermia. Anesthesiology. 1995;82:329-30.

23. Dexter F, Hindman BJ. Computer simulation of brain cooling during cardiopulmonary bypass. Ann Thorac Surg. 1994;57:1171-8; discussion, 1178-9.

24. Englberger L, Suri RM, Greason KL, Burkhart HM, Sundt TM III, Daly RC, et al. Deep hypothermic circulatory arrest is not a risk factor for acute kidney injury in thoracic aortic surgery. J Thorac Cardiovasc Surg. 2011; 141:552-8.

25. Cooper WA, Duarte IG, Thourani VH, Nakamura M, Wang NP, Brown WM III, et al. Hypothermic circulatory arrest causes multisystem vascular endothelial dysfunction and apoptosis. Ann Thorac Surg. 2000;69: 696-702; discussion, 703.

26. Hagl C, Tatton NA, Khaladj N, Zhang N, Nandor S, Insolia S, et al. Involvement of apoptosis in neurological injury after hypothermic circulatory arrest: a new target for therapeutic intervention? Ann Thorac Surg. 2001;72:1457-64.

27. Augoustides JG, Pochettino A, Ochroch EA, Cowie D, Weiner J, Gambone AJ, et al. Renal dysfunction after thoracic aortic surgery requiring deep hypothermic circulatory arrest: definition, incidence, and clinical predictors. $J$ Cardiothorac Vasc Anesth. 2006;20:673-7.

28. Mora Mangano CT, Neville MJ, Hsu PH, Mignea I, King J, Miller DC. Aprotinin, blood loss, and renal dysfunction in deep hypothermic circulatory arrest. Circulation. 2001;104(12 Suppl 1):I276-81.

29. Leshnower BG, Myung RJ, Kilgo PD, Vassiliades TA, Vega JD, Thourani VH, et al. Moderate hypothermia and unilateral selective antegrade cerebral perfusion: a contemporary cerebral protection strategy for aortic arch surgery. Ann Thorac Surg. 2010;90:547-54.

30. Khaladj N, Shrestha M, Meck S, Peterss S, Kamiya H, Kallenbach K, et al. Hypothermic circulatory arrest with selective antegrade cerebral perfusion in ascending aortic and aortic arch surgery: a risk factor analysis for adverse outcome in 501 patients. J Thorac Cardiovasc Surg. 2008;135:908-14.

31. Koullias GJ, Wheatley GH III. State-of-the-art of hybrid procedures for the aortic arch: a meta-analysis. Ann Thorac Surg. 2010;90:689-97.

32. Geisbüsch P, Kotelis D, Müller-Eschner M, Hyhlik-Dürr A, Böckler D. Complications after aortic arch hybrid repair. J Vasc Surg. 2011;53:935-41.

33. Troisi N, Pratesi G, Fargion A, Dorigo W, Pulli R, Acquafresca M, et al. Hybrid treatment of aortic arch aneurysms. J Cardiovasc Surg (Torino). 2010;51:377-82.

34. Etz CD, Plestis KA, Kari FA, Luehr M, Bodian CA, Spielvogel D, et al. Staged repair of thoracic and thoracoabdominal aortic aneurysms using the elephant trunk technique: a consecutive series of 215 first stage and 120 complete repairs. Eur J Cardiothorac Surg. 2008;34:605-14; discussion, 614-5. 